\title{
Article \\ Highly Sensitive and Stable Copper-Based SERS Chips Prepared by a Chemical Reduction Method
}

\author{
Pei Dai, Haochen Li, Xianzhi Huang, Nan Wang and Lihua Zhu *
}

check for updates

Citation: Dai, P.; Li, H.; Huang, X.; Wang, N.; Zhu, L. Highly Sensitive and Stable Copper-Based SERS Chips Prepared by a Chemical Reduction Method. Nanomaterials 2021, 11, 2770. https://doi.org/10.3390/nano11102770

Academic Editors: Ronald Birke and Bing Zhao

Received: 17 September 2021

Accepted: 12 October 2021

Published: 19 October 2021

Publisher's Note: MDPI stays neutral with regard to jurisdictional claims in published maps and institutional affiliations.
School of Chemistry and Chemical Engineering, Huazhong University of Science and Technology, Wuhan 430074, China; peidai94@hust.edu.cn (P.D.); u201810449@hust.edu.cn (H.L.); huangxzh26@mail2.sysu.edu.cn (X.H.); nwang@hust.edu.cn (N.W.)

* Correspondence: lhzhu63@hust.edu.cn

\begin{abstract}
Cu}$ chips are cheaper than Ag and Au chips for practical SERS applications. However, copper substrates generally have weak SERS enhancement effects and poor stability. In the present work, Cu-based SERS chips with high sensitivity and stability were developed by a chemical reduction method. In the preparation process, $\mathrm{Cu}$ NPs were densely deposited onto fabric supports. The asprepared $\mathrm{Cu}$-coated fabric was hydrophobic with fairly good SERS performance. The Cu-coated fabric was able to be used as a SERS chip to detect crystal violet, and it exhibited an enhancement factor of $2.0 \times 106$ and gave a limit of detection (LOD) as low as 10-8 M. The hydrophobicity of the $\mathrm{Cu}$ membrane on the fabric is favorable to cleaning background interference signals and promoting the stability of $\mathrm{Cu}$ NPs to environment oxidation. However, this $\mathrm{Cu}$ SERS chip was still poor in its long-term stability. The SERS intensity on the chip was decreased to $18 \%$ of the original one after it was stored in air for 60 days. A simple introduction of $\mathrm{Ag}$ onto the clean $\mathrm{Cu}$ surface was achieved by a replacement reaction to further enhance the SERS performances of the $\mathrm{Cu}$ chips. The Ag-modified $\mathrm{Cu}$ chips showed an increase of the enhancement factor to $7.6 \times 106$ due to the plasmonic coupling between $\mathrm{Cu}$ and $\mathrm{Ag}$ in nanoscale, and decreased the LOD of CV to 10-11 M by three orders of magnitude. Owing to the additional protection of Ag shell, the SERS intensity of the Cu-Ag chip after a two-month storing maintained $80 \%$ of the original intensity. The Cu-Ag SERS chips were also applied to detect other organics, and showing wide linearity range and low LOD values for the quantitative detection.
\end{abstract}

Keywords: surface-enhanced Raman scattering; copper; SERS chip; chemical reduction; hydrophobicity

\section{Introduction}

Surface-enhanced Raman spectroscopy (SERS), as a highly sensitive vibrational spectroscopy [1], is one of the most commonly used on-field spectroscopic detection techniques with advantages of convenience, rapidness and high sensitivity [2]. Typical SERS active substrates are noble metals $(\mathrm{Au}, \mathrm{Ag}, \mathrm{Cu})$ at nanoscale. A laser can excite their localized surface plasmons resonances (LSPR) and amplify electromagnetic fields, finally leading to the SERS with electromagnetic enhancement mechanism (EM) [3,4]. Among these noble metals, Ag-based substrates produce the strongest Raman enhancement and Au-based substrates have the best long-term stability in air, whereas $\mathrm{Cu}$-based substrates attract the least attention because of their insignificant SERS enhancement and poor stability, although $\mathrm{Cu}$ is much cheaper.

Due to the poorer LSPR of $\mathrm{Cu}$, its electromagnetic enhancement is weaker than that of $\mathrm{Ag}$ and $\mathrm{Au}$. The SERS enhancement factor obtained for simple copper substrates were reported to be $10^{3}-10^{7}[5,6]$, being lower than that of silver $\left(10^{6}-10^{14}\right)$ and gold $\left(10^{4}-10^{9}\right)[7,8]$. In order to improve the SERS performances of $\mathrm{Cu}$ substrates, two strategies are often employed. One is to construct the SERS substrates with compact arrangement of nanoparticles. Kowalska et al. used high pressure for the decomposition of copper hydride $(\mathrm{CuH})$ to prepare SERS platforms with uniformly distributed copper nanocrystals; 
the obtained substrates showed good SERS performance with enhancement factor up to $10^{6}-10^{7}$ [9]. Rao et al. assembled spherical nanocopper into three-dimensional nanoporous $\mathrm{Cu}$ leaves by modifying $\mathrm{Cu}$ NPs with isooctane and polyethylene glycol, and found that the porous 3D structure gave an enhancement factor of $1.2 \times 10^{6}$ [10]. The other is to combine copper with other materials [11]. Dizajghorbani-Aghdam et al. co-deposited $\mathrm{Cu}$ NPs with a graphitic carbon nitride ( $\mathrm{gCN}$ ) support, and found that the $\mathrm{Cu} / \mathrm{gCN}$ hybrids showed strong absorption in the visible light to near-IR range, resulting in an enhancement factor of $10^{7}$ [12].

Copper is chemically active in air, and hence $\mathrm{Cu}$ NPs are easy to aggregate irregularly and to be oxidized, leading to the decrease of the enhancement effect. Loading Cu NPs onto the fixed substrates, such as Si wafer [13,14], glass [15], polystyrene spheres [16] and graphene oxide (GO) [17], could prevent the random aggregation of colloidal copper. A compact arrangement of $\mathrm{Cu}$ NPs may produce abundant hot spots with fairly high enhancement effect with improved SERS performances. Surface coating of noble metal nanoparticles is a common method to prevent oxidation [18,19]. The size and morphology of nanocopper can be controlled by modifying surfactants on the surface of copper, and the obtained coating can also hamper the aggregation and oxidation of $\mathrm{Cu}$ NPs. Zhang et al. encapsulated Cu NPs in a graphene shell (thickness: $1 \mathrm{~nm}$ ) to improve the stability of $\mathrm{Cu}$ NPs [20]. Compared with traditional SERS coatings of metallic NPs, such as $\mathrm{SiO}_{2}$ [21], polymers [22] and amorphous carbon [23], the few layers of graphene could strengthen the plasmonic coupling between graphene and $\mathrm{Cu}[24]$, exhibiting an enhancement factor of $1.15 \times 10^{6}$.

Copper-based SERS chips have been prepared with various methods though chemical reduction [25,26], electrochemical deposition [27], aerosol direct writing [28], subsequent dealloying process [29], magnetron sputtering [30], laser ablation [12] and chemical vapor deposition (CVD) [20]. Among these methods, the chemical and electrochemical reduction processes are ubiquitous and convenient to operate without the needs of high temperature, high level of vacuum and expensive instruments. However, the surface of $\mathrm{Cu}$ NPs produced by solution chemistry techniques may be contaminated by the added stabilizing agent, such as polyvinyl pyrrolidone [31], sodium dodecylbenzene sulphonate [32] or cetyltrimethylammonium bromide [33], the residues of which easily lead to disturbances in high-sensitivity detection.

In the present work, we successfully developed the Ag-modified Cu SERS chip with high sensitivity and stability by a chemical reduction method. By loading Cu NPs on the fabric, the random aggregation of colloidal copper was avoided. The compact arrangement of $\mathrm{Cu}$ NPs leads to the hydrophobicity and sensitivity of the copper-based SERS chip. Without any modifier to hinder SERS performance and create interference signals, the $\mathrm{Cu}$ substrate had a clean background. Silver could be directly deposited onto the surface-clean $\mathrm{Cu}$-coated fabric by a replacement reaction. The introduction of $\mathrm{Ag}$ further strengthened the plasmonic coupling between $\mathrm{Cu}$ and $\mathrm{Ag}$, therefore contributing to an improved sensitivity. The hydrophobicity of the copper membrane was of great importance because a hydrophobic surface could improve the stability of materials [34]. Being benefit from the hydrophobic effect of the hydrophobic surface and the protection from the thin silver shell, the as-prepared SERS chips had good stability in air. We should note that it looked strange but is very interesting that the SERS performances of the mildly oxidized SERS substrate could be partially recovered by a vacuum deoxygenation treatment. Owing to the contribution of chemical enhancement mechanism (CM) in this $\mathrm{Cu}$-Ag chip, the target molecules with required energy levels could be selective enhanced and quantitative detected through the photo-induced charge transfer (PICT).

\section{Experimental Section}

\subsection{Reagents}

$\mathrm{N}_{2} \mathrm{H}_{4} \cdot \mathrm{H}_{2} \mathrm{O}(85 \%), \mathrm{H}_{2} \mathrm{O}_{2}(30 \%)$, crystal violet $(\mathrm{CV})$ and ethanol were purchased from Sinopharm Chemical Reagent Co., Ltd (Shanghai, China). $\mathrm{Cu}\left(\mathrm{CH}_{3} \mathrm{COO}\right)_{2} \cdot \mathrm{H}_{2} \mathrm{O}$ and $\mathrm{AgNO}_{3}$ 
were purchased from Shanghai Lingfeng Chemical Reagents Co., Ltd (Shanghai, China). Paraquat (PQ) was purchased from Macklin (Shanghai, China). Sibutramine hydrochloride (SH) was obtained from the National Institute for the Control of Pharmaceutical and Biological Products (Beijing, China). All the chemicals were analytically pure and used as received without further purification. Deionized water was used throughout the experiments.

\subsection{Preparation of Flexible Hydrophobic Ag Modified Copper SERS Chips}

The flexible SERS chips were chemically prepared by depositing hydrophobic $\mathrm{Cu}$ membrane on fabrics and then coating sliver on the $\mathrm{Cu}$ membrane through a replacement reaction. In the first step, copper was coated on fabrics with a modified chemical deposition procedure as reported [35]. Fabrics were cut into pieces with sizes of $2 \mathrm{~cm} \times 2 \mathrm{~cm}$, followed by fully washing with water and ethanol. After being dried, the cleaned fabric was fully immersed in a solution of copper acetate $\left(20 \mathrm{~mL}, 10 \mathrm{~g} \mathrm{~L}^{-1}\right)$ for several minutes. Then, $800 \mu \mathrm{L}$ of $80 \%$ hydrazine hydrate was added to it drop by drop under mild stirring. The reaction in the mix solution was kept at room temperature for $6 \mathrm{~h}$, which allowed the deposition of copper particles onto the fabric. Afterward, the prepared $\mathrm{Cu}$-coated fabric was taken out and washed with water and ethanol, followed by vacuum drying at $60{ }^{\circ} \mathrm{C}$ for $1 \mathrm{~h}$. The obtained $\mathrm{Cu}$ membrane on the fabric was confirmed to be hydrophobic. In the present work, this sample was also used as a SERS chip, being referred to as a hydrophobic Cu chip.

In the second step, Ag particles were further deposited on the above obtained $\mathrm{Cu}$ coated fabric by immersing it in a solution of $\mathrm{AgNO}_{3}(0.01 \mathrm{M})$ in ethanol for $1 \mathrm{~min}$. Then, the fabric was washed with water and ethanol, and vacuum dried at $60^{\circ} \mathrm{C}$ for $1 \mathrm{~h}$. This product was flexible hydrophobic Ag modified copper SERS chips, being referred to as a hydrophobic $\mathrm{Cu}-\mathrm{Ag}$ chip. If not specified elsewhere, these two types of the chips were used in the SERS measurements after they were carefully cut into small pieces with a size of $0.5 \mathrm{~cm} \times 0.5 \mathrm{~cm}$.

\subsection{Characterization}

Scanning electron microscopy (SEM) characterization was performed on a GeminiSEM 300 (ZEISS, Heidenheim, Germany). X-ray diffraction (XRD) patterns were recorded by a SmartLab-SE diffractometer (Rigaku, Tokyo, Japan). Contact angles were obtained on an OCA20 optical contact angle meter (Dataphysics, Filderstadt, Germany). UV-vis diffuse reflectance spectra were obtained by a UV-3600 UV-VIS-NIR spectrophotometer (Shimadzu, Kyoto, Japan) in diffuse reflectance mode. XPS analysis was conducted on a K-Alpha X-ray photoelectron spectrometer (Thermo Scientific, Carlsbad, CA, USA).

\subsection{SERS Detection}

The specified SERS chip was immersed in the ethanol solution of analytes for $10 \mathrm{~min}$, and then it was taken out for SERS detection. The SERS detection was performed with a ATR8100 portable Raman spectrometer (Optosky, Xiamen, China). A $785 \mathrm{~nm}$ laser was used as an excitation source with a laser power of $50 \mathrm{~mW}$, and the exposure time of $5 \mathrm{~s}$ was set without accumulation. During the measurement, the fabric support in the chip was kept wet by adding ethanol. The detection was performed five times at different positions on the tested SERS chip, and the averaged spectrum was used for further analysis.

The Raman enhancement factor was calculated with the following equation:

$$
E F=\frac{I_{S E R S} \times N_{N R}}{N_{S E R S} \times I_{N R}}
$$

where $I_{S E R S}$ and $I_{N R}$ are the intensity of the same peaks position in the SERS spectrum and normal Raman spectrum, respectively, $N_{S E R S}$ represents the number of adsorbed molecules in the SERS analysis and $N_{N R}$ is the number of molecules in the scattering volume. 


\subsection{Stability Experiment}

To evaluate the oxidation resistance of the substrate, a newly made SERS chip was firstly used to detect the original SERS signal of CV $\left(\mathrm{I}_{0}\right)$. Then, it was stored in the air for different periods of time and then measured the SERS intensity $\left(\mathrm{I}_{\mathrm{t}}\right)$. The time course of the $\mathrm{I}_{\mathrm{t}} / \mathrm{I}_{0}$ value was used to evaluate the stability of the chip for its endurance to the oxidation of substrate.

To recover of the SERS performance of the oxidized SERS substrate, the "oxidized" chip was vacuum dried at $60^{\circ} \mathrm{C}$ for $2 \mathrm{~h}$. The vacuum dried "recovered" chip was used for the SERS detection. Here, the so-called "oxidized" chip was obtained by immersing the "freshly prepared" chip for about $30 \mathrm{~min}$ in the ethanol solution of $0.01 \mathrm{M} \mathrm{H}_{2} \mathrm{O}_{2}$, which was prepared by dissolving a required amount of $\mathrm{H}_{2} \mathrm{O}_{2}(30 \%)$ into ethanol. After it was washed with ethanol and air dried, it was used to measure the SERS performance.

\section{Results and Discussion}

\subsection{Characterizations of the $\mathrm{Cu}$ and $\mathrm{Cu}-\mathrm{Ag}$ Chips}

In the $\mathrm{Cu}$ chip, the fabric was used as the carrier to locate copper nanoparticles and prevent the spontaneous aggregation of them, while $\mathrm{Cu}$ NPs were evenly deposited on the fabric by a simple chemical reduction method with hydrazine hydrate as a reducing agent. The as-prepared $\mathrm{Cu}$-coated fabric chip had a deep red color with copper evenly deposited on the filaments. The SEM image of the $\mathrm{Cu}$ coating on the fabric (Figure 1a-c) showed that the amount of deposited copper increased and the $\mathrm{Cu}$ NPs became bigger with a prolonged deposition time. For the Cu coating with deposition time of $6 \mathrm{~h}$ (being referred to as $6 \mathrm{~h}$ $\mathrm{Cu}$ ), the $\mathrm{Cu}$ NPs with sizes of about 100-200 nm were packed together closely (Figure $1 \mathrm{~b}$ ). The packing-induced micro-nano structure of the deposited $\mathrm{Cu}$ NPs made the surface of the fabric chip hydrophobic, yielding a contact angle of $144.0^{\circ}$ (Figure 1d) for $6 \mathrm{~h} \mathrm{Cu}$. The EDS mapping of $\mathrm{Cu}$ on the $\mathrm{Cu}$ coating (Figure 1i) confirmed the even distribution of $\mathrm{Cu}$ on the surface of the fabric.

After the $6 \mathrm{~h} \mathrm{Cu}$ sample was treated by immersion in a solution of AgNO3 $(0.01 \mathrm{M})$ in ethanol, the $\mathrm{Cu}$ chip was converted to the $\mathrm{Cu}-\mathrm{Ag}$ chip, which was similarly characterized. The SEM image (Figure 1e-g) demonstrated that the Ag NPs covered on Cu NPs generated from the discrete small particles to the monolithic structure. As shown in Figure 1e, the aggregated $\mathrm{Cu}$ NPs were covered by much smaller particles on the $\mathrm{Cu}-\mathrm{Ag}$ coating with $1 \mathrm{~min}$ replacement time ( $6 \mathrm{~h} \mathrm{Cu}-1 \mathrm{~min} \mathrm{Ag}$ ). This is possibly related to the following processes: the replacement reaction led to the generation of Ag NPs with smaller particle sizes and also thinned the out-most $\mathrm{Cu}$ particles through the partial dissolution of $\mathrm{Cu}$. Due to the deposition of $\mathrm{Ag}$, the fabric chip became dark in color, indicating the deposition of $\mathrm{Ag}$ NPs with small sizes. The EDS mapping of $\mathrm{Cu}$ and $\mathrm{Ag}$ on the $\mathrm{Cu}-\mathrm{Ag}$ chip (Figure $1 \mathrm{j}, \mathrm{k}$ ) confirmed the even distribution of both $\mathrm{Cu}$ and $\mathrm{Ag}$ on the surface of the fabric. The deposition amount of $\mathrm{Ag}$ was little, and atomic ratio of $\mathrm{Cu}$ : $\mathrm{Ag}$ was around 7:1. The easy detection of $\mathrm{Cu}$ under the Ag layer by EDS mapping also signed that the outermost layer of Ag was very thin. This thin layer did not change the hydrophobic nature of the preobtained $\mathrm{Cu}$ layer, and hence the contact angle on the surface of the $\mathrm{Cu}-\mathrm{Ag}$ chip was still as large as $141.5^{\circ}$ (Figure $1 \mathrm{~h}$ ). The relationship between SERS performance and structural morphology of $\mathrm{Cu}$ and $\mathrm{Cu}-\mathrm{Ag}$ chip will be discussed later.

The crystal structures and chemical structures of the $\mathrm{Cu}$ and $\mathrm{Cu}-\mathrm{Ag}$ chips were investigated by XRD and XPS analysis. As shown in Figure 2a, the XRD patterns of the Cu coating showed two peaks at $43.3^{\circ}$ and $50.5^{\circ}$, which matched well with the diffraction peaks of (1 111 ) and (2 00 ) for the Cu metal (JCPDS 04-0836). Figure 2b showed Cu 2p XPS spectra of the copper coating. There were only two spin-orbit splitting components of 2p1/2 (952 eV) and $2 \mathrm{p} 3 / 2(932 \mathrm{eV})$ without the satellite peaks around $943 \mathrm{eV}$, further indicating the state of metallic copper. 

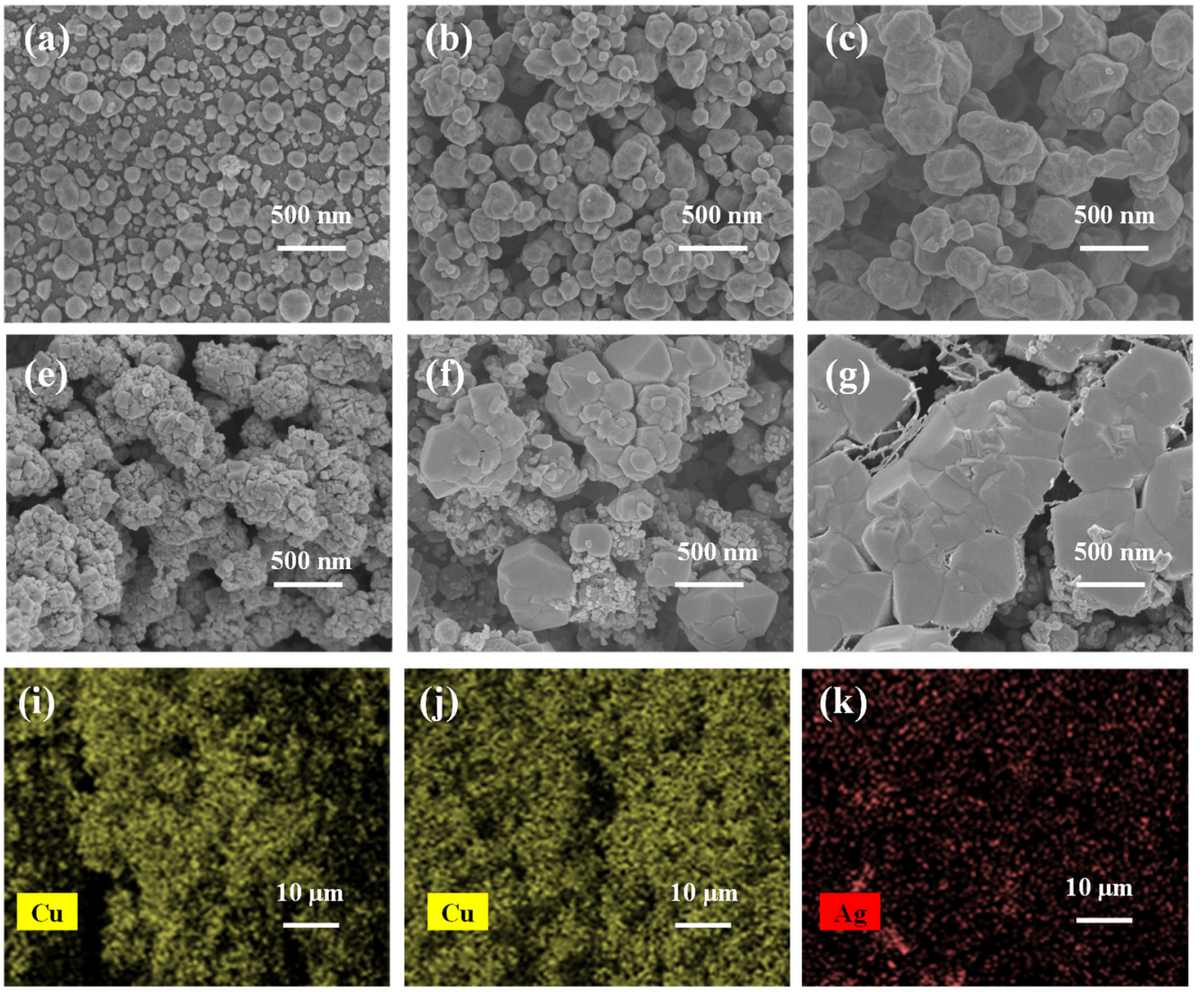

(d)
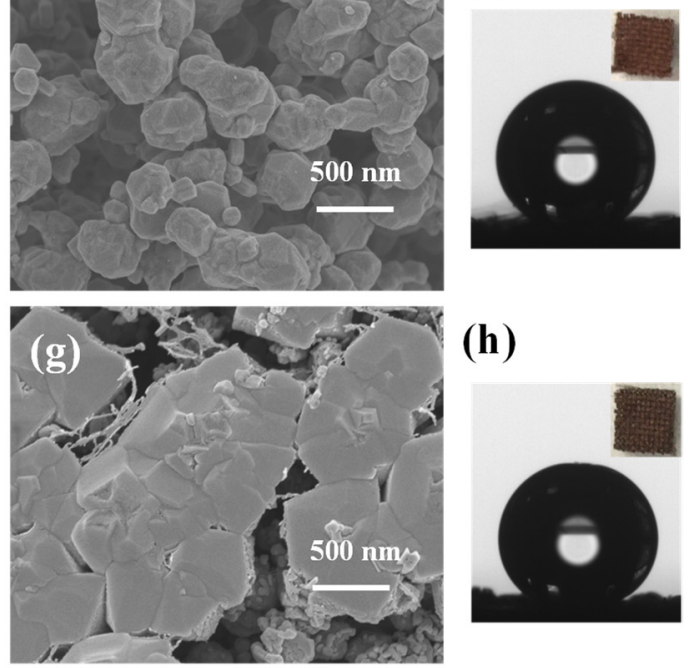

(h)

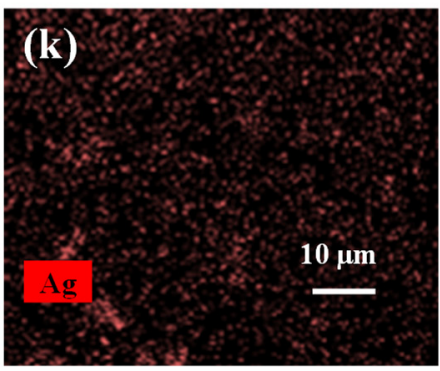

Figure 1. Characterization of $\mathrm{Cu}$ and $\mathrm{Cu}-\mathrm{Ag}$ chips. (a-c,e-g) SEM images of the Cu coating with Table $1 . \mathrm{h}$, (b) $6 \mathrm{~h}$, (c) $12 \mathrm{~h}$ and $\mathrm{Cu}-\mathrm{Ag}$ coating with the replacement time of (e) $1 \mathrm{~min}$, (f) $3 \mathrm{~min}$ and (g) $5 \mathrm{~min}$. (d,h) Contact angles of the coatings of $6 \mathrm{~h} \mathrm{Cu}(\mathbf{d})$ and $6 \mathrm{~h} \mathrm{Cu}-1 \mathrm{~min} \mathrm{Ag}(\mathrm{h})$ on the fabric together with their photos in the inset. (i) EDS mapping of $\mathrm{Cu}$ on the $\mathrm{Cu}$ coating. (j,k) EDS mapping of $\mathrm{Cu}(\mathbf{j})$ and $\mathrm{Ag}(\mathbf{k})$ on the $\mathrm{Cu}-\mathrm{Ag}$ coating.

Table 1. Comparison between copper-based SERS chips prepared by various methods.

\begin{tabular}{|c|c|c|c|c|c|}
\hline SERS Substrate & Preparation Method & Targets & LOD (M) & EF & Ref. \\
\hline $\mathrm{Cu} / \mathrm{gCN}$ & pulsed laser ablation & $\begin{array}{l}\mathrm{CV} \\
\mathrm{R} 6 \mathrm{G}\end{array}$ & $\begin{array}{l}10^{-7} \\
10^{-6}\end{array}$ & $\begin{array}{l}7.2 \times 10^{7} \\
1.3 \times 10^{7}\end{array}$ & [12] \\
\hline Cu NPs/Si wafer & $\mathrm{Si}-\mathrm{H}$ bond assembly & R6G & $10^{-9}$ & $2.3 \times 10^{7}$ & [14] \\
\hline Cu-doped glass & thermal annealing & $\mathrm{RhB}$ & $10^{-9}$ & $1.5 \times 10^{8}$ & [15] \\
\hline Cu NP arrays & ion-sputtering deposition & 4-ATP & $10^{-7}$ & $1.6 \times 10^{7}$ & [16] \\
\hline Cu@G-NGNs & chemical vapor deposition & R6G & $10^{-7}$ & $1.1 \times 10^{6}$ & [20] \\
\hline $\mathrm{Cu}$ NPs & aerosol direct writing & $\mathrm{RhB}$ & $10^{-6}$ & $2.1 \times 10^{5}$ & [28] \\
\hline nanoporous $\mathrm{Cu}$ & subsequent dealloying & R6G & $10^{-9}$ & $4.7 \times 10^{7}$ & [29] \\
\hline Cu nanoislands & magnetron sputtering & 4-ATP & $10^{-7}$ & $4.0 \times 10^{4}$ & [30] \\
\hline mesoporous $\mathrm{Cu}$ films & electrochemical deposition & R6G & $10^{-6}$ & $3.8 \times 10^{5}$ & [27] \\
\hline $\mathrm{Cu} / \mathrm{rGO}$ & $\begin{array}{c}\text { chemical reduction with rGO as } \\
\text { stabilizing agent }\end{array}$ & $\mathrm{CV}$ & / & / & [17] \\
\hline $\mathrm{Cu}$ NPs & $\begin{array}{c}\text { chemical reduction with gelatin as } \\
\text { stabilizing agent }\end{array}$ & $\mathrm{CV}$ & / & $3.6 \times 10^{3}$ & [25] \\
\hline $\mathrm{Cu}$ NPs & $\begin{array}{c}\text { chemical reduction with octadecylamine } \\
\text { as stabilizing agent }\end{array}$ & RhB & / & $8.6 \times 10^{3}$ & [26] \\
\hline $\begin{array}{l}\text { 3D nanoporous } \mathrm{Cu} \\
\text { leaves }\end{array}$ & $\begin{array}{c}\text { chemical reduction with isooctane/PEG } \\
\text { as stabilizing agent }\end{array}$ & 4-MBA & / & $1.2 \times 10^{6}$ & [11] \\
\hline $\begin{array}{c}\text { Cu-coated fabric } \\
\text { Cu-Ag-coated fabric }\end{array}$ & $\begin{array}{c}\text { chemical reduction without any } \\
\text { stabilizing agent }\end{array}$ & $\mathrm{CV}$ & $\begin{array}{c}10^{-8} \\
10^{-11}\end{array}$ & $\begin{array}{l}2.0 \times 10^{6} \\
7.6 \times 10^{6}\end{array}$ & This work \\
\hline
\end{tabular}


(a)

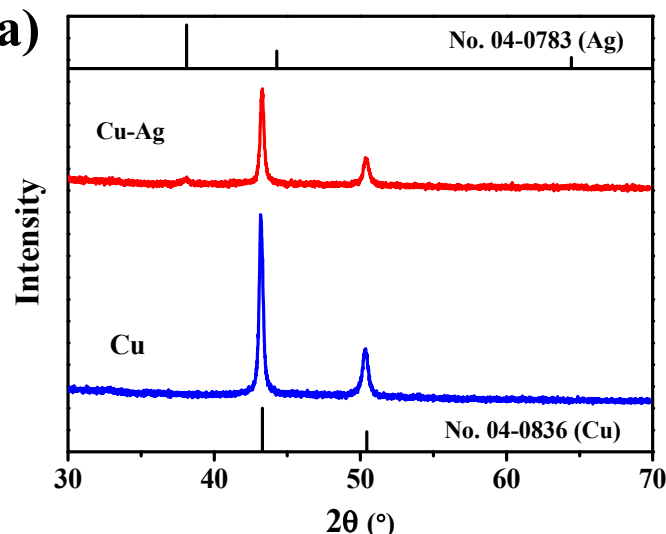

(c)

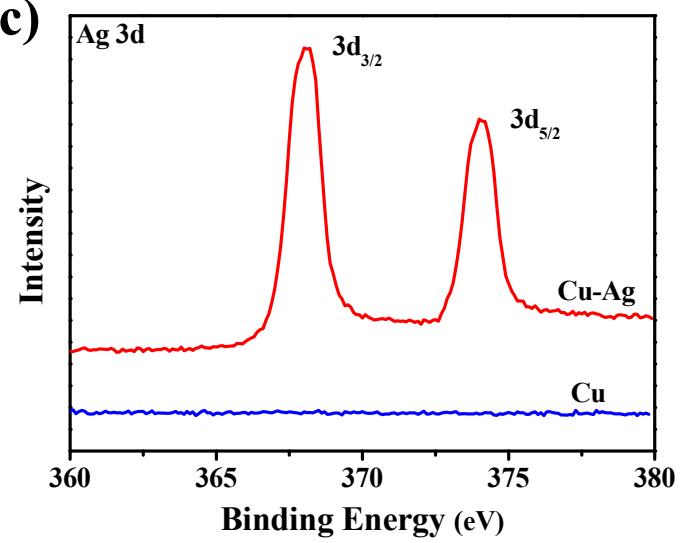

(b)

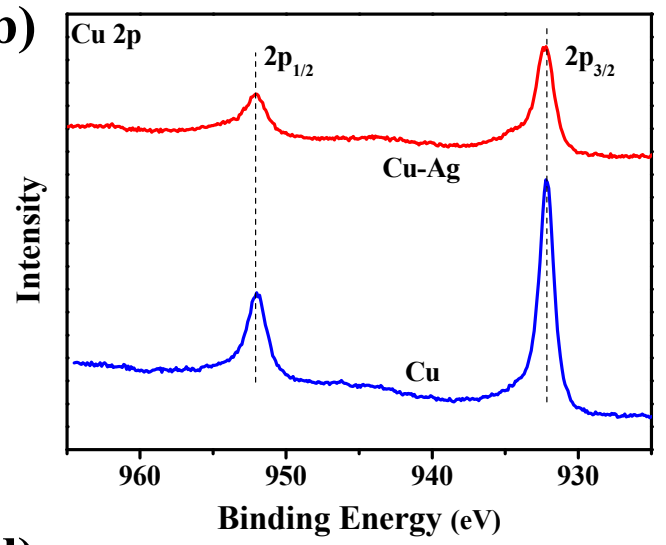

(d)

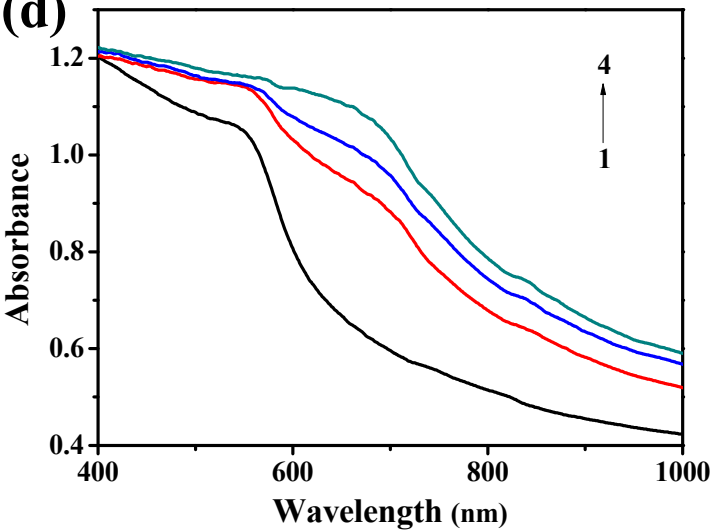

Figure 2. XRD patterns (a), XPS high resolution spectra of $\mathrm{Cu} 2 \mathrm{p}(\mathbf{b}), \mathrm{Ag} 3 \mathrm{~d}$ (c) of the $\mathrm{Cu}$ and $\mathrm{Cu}-\mathrm{Ag}$ chips. (d) VIS-NIR diffuse reflectance spectra of Cu-based fabrics with the Ag replacement Table 1. 0, (2) 1, (3) 3 and (4) 5 min in the preparation.

The XRD pattern showed that a new diffraction peak appeared at $38.3^{\circ}$ (Figure 2a), corresponding to the (1 111 ) crystal plane of silver (JCPDS 04-0783). As shown in the Cu 2p XPS spectra (Figure 2b), the two characteristic peaks of metallic copper at $932 \mathrm{eV}\left(\mathrm{Cu} 2 \mathrm{p}_{3 / 2}\right)$ and $952 \mathrm{eV}\left(\mathrm{Cu} 2 \mathrm{p}_{1 / 2}\right)$ were observed for the $\mathrm{Cu}-\mathrm{Ag}$ chip like that in the case of the $\mathrm{Cu}$ chip. Due to the covering by the thin $\mathrm{Ag}$ layer, the intensities of these $\mathrm{Cu}$ peaks were decreased slightly. The XPS Ag 3d spectra (Figure 2c) of the $\mathrm{Cu}$-Ag-coated fabric showed two peaks at $374 \mathrm{eV}\left(\mathrm{Ag} \mathrm{3d_{3/2 }}\right)$ and $368 \mathrm{eV}\left(\mathrm{Ag} \mathrm{3} \mathrm{d}_{5 / 2}\right)$, indicating the deposition of metallic silver.

Figure $2 \mathrm{~d}$ showed the VIS-NIR diffuse reflectance spectra of the $\mathrm{Cu}$-coated fabrics with different deposition times of Ag. The surface plasmon resonance (SPR) peak of $\mathrm{Cu}$ coating appeared at $556 \mathrm{~nm}$, and the introduction of Ag enhanced this absorption and generated a new SPR peak in the near infrared region. Along with the growing of the Ag shell, the SPR peak in the near infrared region was blue shifted from $705 \mathrm{~nm}$ to $672 \mathrm{~nm}$ until it attenuated the SPR peak of $\mathrm{Cu}$ to merge into a single peak. This might influence the SERS performances of the chip, as discussed later.

\subsection{SERS Performances of the $\mathrm{Cu}$ Chip}

In the $\mathrm{Cu}$ chip, metallic copper nanoparticles were deposited on the fabric and generated to a hydrophobic surface, which is possibly favorable to its SERS performance. As shown in Figure 3a, the $\mathrm{Cu}$ deposition time (and hence the deposition amount) influenced the SERS responses of $\mathrm{CV}$ on the $\mathrm{Cu}$ chip. By using the intensity of the strongest peak of $C V$ at $1617 \mathrm{~cm}^{-1}$, the SERS signal intensity was plotted against the deposition time in Figure $3 \mathrm{~b}$. When increasing the deposition time from 0 to $6 \mathrm{~h}$, the SERS signals of CV were rapidly increased from 0 to 1300 a.u.; further increasing the deposition time from 6 to $24 \mathrm{~h}$ decreased the SERS signal intensity, but finally keeping at 250 a.u. at about $24 \mathrm{~h}$. The $\mathrm{Cu}$ deposition time mainly affected the individual $\mathrm{Cu}$ particles (the particle sizes, packing patterns) and the hydrophobicity of the surface. The hydrophobicity of the surface was 
monitored by measuring the contact angle. As shown in Figure 3b, once the Cu filmed was formed on the fabric, the contact angle was greater than $120^{\circ}$, showing hydrophobicity. For example, the contact angle of the chip surface with deposition time of 6 and $12 \mathrm{~h}$ was measured to be $144.0^{\circ}$ and $150^{\circ}$, respectively. Because the deposition time dependence of the SERS signal intensity was greatly different from the deposition time dependence of the contact angle in the curve shape as shown in Figure $3 b$, the weak variation of the surface hydrophobicity would not be an important factor influencing the deposition time dependence of the SERS signal intensity. Therefore, the surface morphology of the chip was checked for different periods of deposition time. As shown in Figure 1a-c, the size of $\mathrm{Cu}$ NPs gradually increased and packed together with the prolonging of deposition time. When the deposition time is $1 \mathrm{~h}$ (Figure 1a), the Cu NPs deposited on the fabric was small and loose with the size of $80 \mathrm{~nm}$. When the deposition time was prolonged to $6 \mathrm{~h}$ (Figure $1 \mathrm{~b}$ ), the amount and diameter of $\mathrm{Cu}$ deposition on the fabric increased significantly, a large number of Cu NPs (100-200 nm) tightly packing to form hot spots. Further extended the deposition time to $12 \mathrm{~h}$ (Figure 1c), the small size $\mathrm{Cu}$ NPs merged to form large $\mathrm{Cu}$ NPs with the size of around $300 \mathrm{~nm}$, so the surface roughness and number of hot spots decreased. Based on the above discussions, the $\mathrm{Cu}$ deposition time was selected at $6 \mathrm{~h}$ hereafter.

(a)

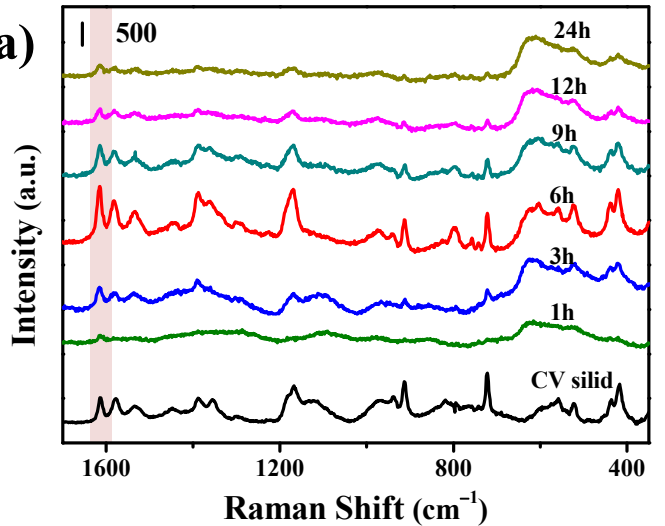

(c)

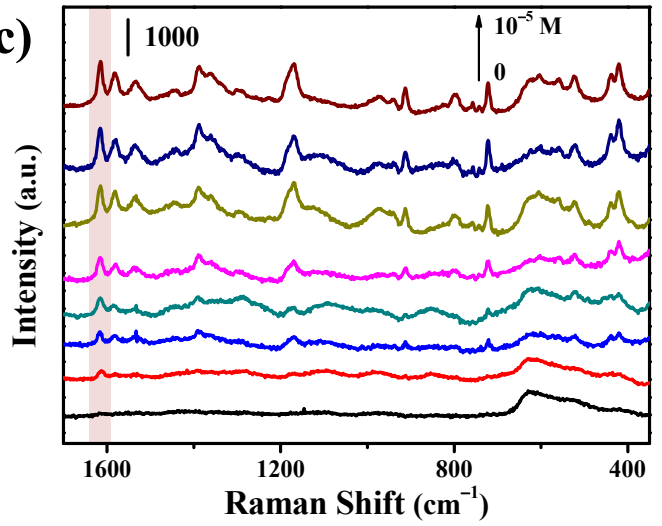

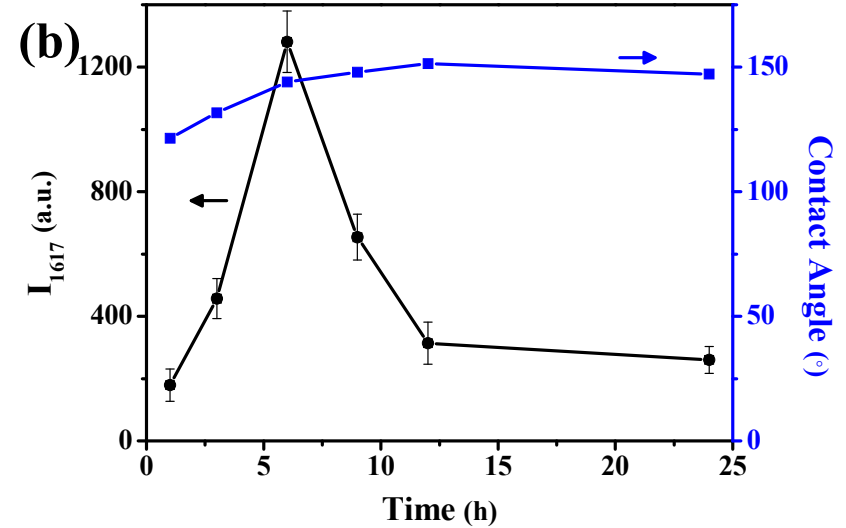

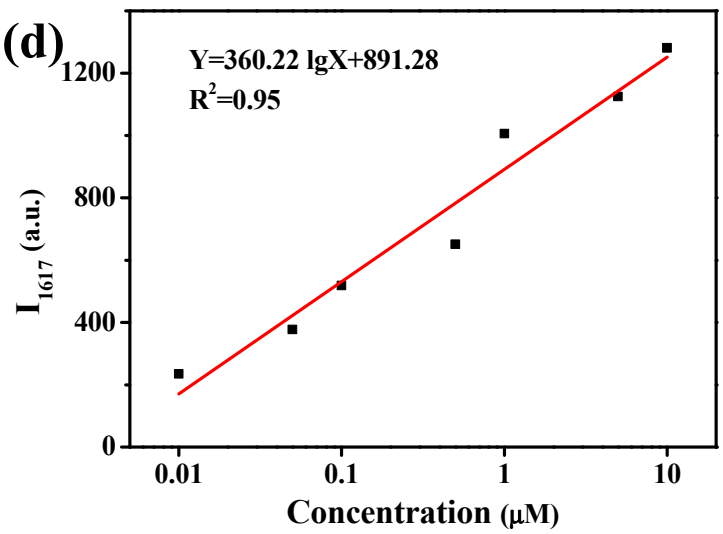

Figure 3. SERS performances of the Cu chip. (a) SERS spectra of $1 \mathrm{ppm} \mathrm{CV}$ on the Cu chips prepared with the different deposition time. (b) Influences of the Cu deposition time on the peak intensity of CV at $1617 \mathrm{~cm}^{-1}$ and the contact angle of the chip surface. (c) SERS spectra of CV at various concentrations on the Cu chips. (d) A plot of the peak intensity of CV at $1617 \mathrm{~cm}^{-1}$ against CV concentration.

By using the sharp peak of $\mathrm{CV}$ at $1617 \mathrm{~cm}^{-1}$, the enhancement factor (EF) of the $\mathrm{Cu}$ chip was evaluated to be $2.0 \times 106$. Table 1 compared the EF values of the copperbased SERS chips prepared by various methods. This comparison indicated that the SERS performance of the presently developed $\mathrm{Cu}$ chip was somewhat poorer than that prepared by expensive physical methods (about 107), but much higher than that prepared by other chemical reduction methods (103-105). This was possibly related to the slow deposition of 
$\mathrm{Cu}$ in the present work, leading to more tightly packing of $\mathrm{Cu}$ NPs for the generation of more hot spots in the chip. In our method, no any organic stabilizing agents were used, and hence the $\mathrm{Cu}$-coated fabric exhibited a clean background without interference peaks (Figure 3c). We measured the SERS spectra of CV at different concentrations (Figure 3c), and plotted the peak intensity at $1617 \mathrm{~cm}^{-1}$ against the $\mathrm{CV}$ concentration (Figure $3 \mathrm{~d}$ ). It was found that the SERS intensity was linearly correlated with the logarithm of CV concentration in the range of $10^{-8}-10^{-5} \mathrm{M}$, with a LOD of $10^{-8} \mathrm{M}$.

\subsection{SERS Performances of the Cu-Ag Chip}

As shown in Table 1, the SERS performance of the presently prepared $\mathrm{Cu}$ chip needs to be promoted further in comparison with the best ones. More importantly, we found that the SERS performance of the $\mathrm{Cu}$ chip was decreased greatly after it was stored in air for several weeks due to its poor oxidation resistance (more details will be described in the next section). Therefore, it was required to further increase the SERS enhancing effect and the oxidation resistance of the SERS substrate. As we know, metallic Ag has stronger intrinsic SERS effect and is much more inert in air than metallic $\mathrm{Cu}$. Therefore, our strategy was to cover a very thin layer of nano- $\mathrm{Ag}$ on the $\mathrm{Cu}$ chip by immersion plating.

As shown in Figure $4 \mathrm{a}$, as the replacement time of $\mathrm{Ag}$ was prolonged from 0 to $1 \mathrm{~min}$, the Ag-modified $\mathrm{Cu}$ chip yielded a fast increasing of the SERS signal intensity (at $1617 \mathrm{~cm}^{-1}$ ) from 1281 to 4275 a.u. together with an increase of the enhancement factor to $7.6 \times 106$. This was explained by considering the effects of the deposited Ag: the deposited Ag NPs increased the surface roughness (as confirmed by the SEM observation in Figure 1e), being favorable to producing more hot spots; the initially deposited Ag NPs had a SPR peak at $705 \mathrm{~nm}$, which matched better with the laser excitation of $785 \mathrm{~nm}$. When the replacement time of Ag was more than $3 \mathrm{~min}$, the SPR peak blue shifted, and its SERS performance decreased. This may because that the Ag covered the $\mathrm{Cu}$, shielding the contribution of inner $\mathrm{Cu}$. Figure $1 \mathrm{e}-\mathrm{g}$ showed the SEM image of $\mathrm{Cu}-\mathrm{Ag}$ chip with the replacement time of 1-5 min. With the prolonging of replacement time of Ag from 1 to $5 \mathrm{~min}$, the $\mathrm{Cu}$ further dissolved, the $\mathrm{Ag}$ became larger to completely coat the $\mathrm{Cu}$ NPs (Figure 1f) and finally generated the Ag particles in micro scale (Figure 1g). Beyond that, Ag with higher surface energy was more easily wetted by water than $\mathrm{Cu}$. Therefore, the contact angle of the $\mathrm{Cu}$-based chip decreased to $141.5^{\circ}$ with the increase of silver content, and finally tended to be stable due to the Ag completely covering the $\mathrm{Cu}$ (Figure $4 \mathrm{a}$ ). Therefore, in the present work, the Ag deposition time was selected at $1 \mathrm{~min}$ for preparing the Cu-Ag chip.

The SERS spectra of CV at various concentrations were recorded on the Cu-Ag chip as shown in Figure $4 \mathrm{~b}$. In comparison with the spectra recorded on the $\mathrm{Cu}$ chip for the specified individual concentrations of $\mathrm{CV}$ (Figure $3 \mathrm{c}$ ), the spectra recorded on the $\mathrm{Cu}-\mathrm{Ag}$ chip were much enhanced in the peak intensity. From the plot of the peak intensity at $1617 \mathrm{~cm}^{-1}$ against the CV concentration (Figure 4c), it was found that there was a linear correspondence between the SERS intensity and the logarithm of CV concentration in the range of $10^{-9}-10^{-6} \mathrm{M}$, with an LOD as low as $10^{-11} \mathrm{M}$.

In order to evaluate the uniformity of the as-prepared SERS chips, 50 points on the same $\mathrm{Cu}$-Ag chip were selected randomly to detect the SERS signals. As shown in Figure 4c, the signal intensity of $\mathrm{CV}$, especially for its strongest peak at $1617 \mathrm{~cm}^{-1}$, was very close to each other. Furthermore, we acquired the SERS spectra of $\mathrm{CV}$ at $1 \mathrm{mg} \cdot \mathrm{L}^{-1}$ on ten $\mathrm{Cu}-\mathrm{Ag}$ chips as shown in Figure $4 \mathrm{~d}$, and found that these spectra were also very close to each other with the relative standard deviation of only $12.6 \%$. These demonstrated that the presently developed $\mathrm{Cu}-\mathrm{Ag}$ chips have good reproducibility in term of both intra- and inter-batches. 

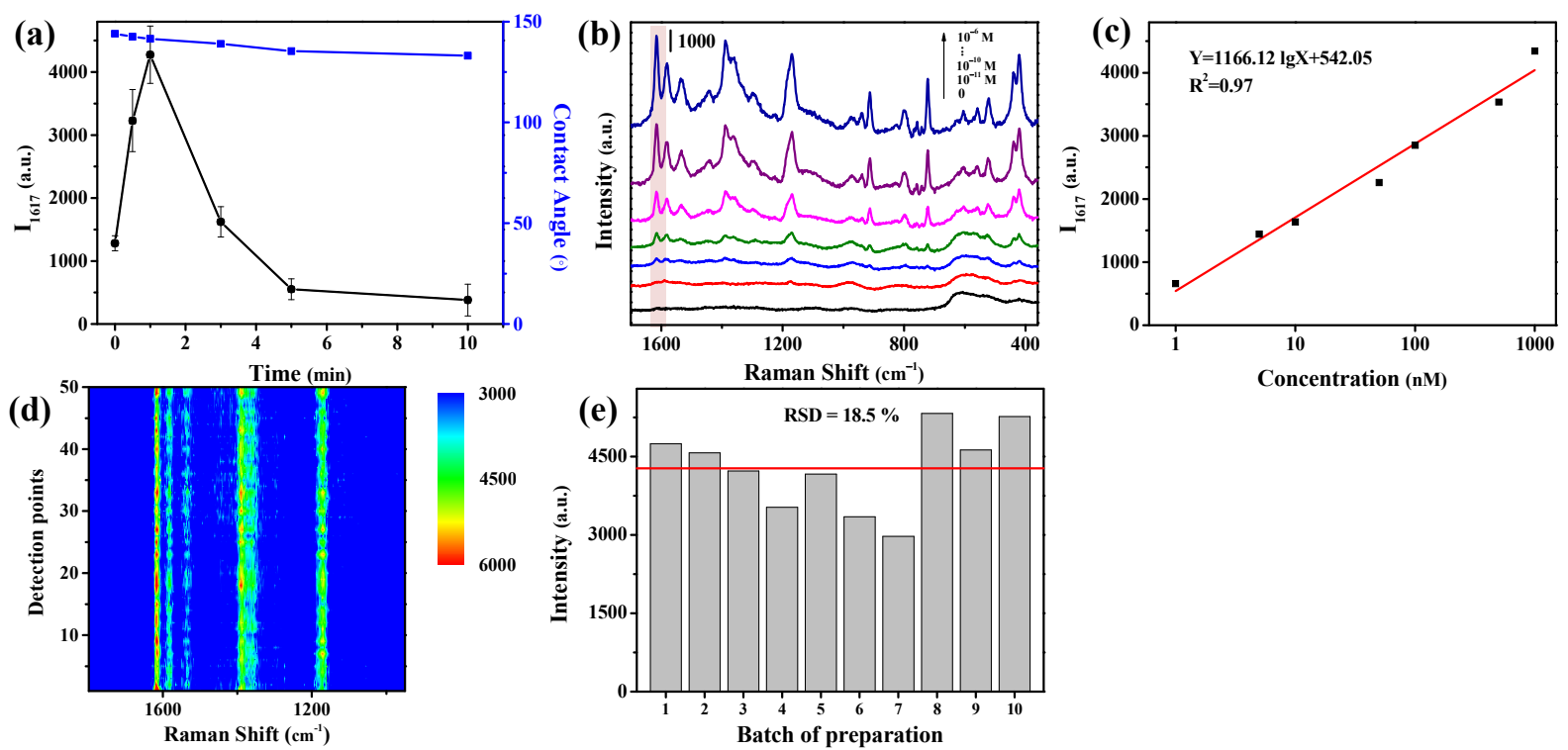

Figure 4. SERS performance of the $\mathrm{Cu}-\mathrm{Ag}$ chip. (a) Effects of the replacement time of sliver on the peak intensity of $\mathrm{CV}$ at $1617 \mathrm{~cm}^{-1}$ and the contact angle of the chip surface. (b) SERS spectra of CV at various concentrations on the Cu-Ag chip. (c) A plot of peak intensity of $\mathrm{CV}$ at $1617 \mathrm{~cm}^{-1}$ on the $\mathrm{Cu}-\mathrm{Ag}$ chip against CV concentration. Reproducibility of SERS signals obtained on the (d) intra-batch and (e) inter-batch $\mathrm{Cu}-\mathrm{Ag}$ chips.

\subsection{Stability of the Cu-Based SERS Chips}

The resistance of copper to air oxidation is not so good, and the oxidative corrosion of $\mathrm{Cu}$ may decrease the SERS performances of the $\mathrm{Cu}$ chips. By using the characteristic peak of $C V$ at $1617 \mathrm{~cm}^{-1}$ as a reference, we recorded the original peak intensity on the newly prepared chip (I0) and the peak intensity (It) after the chip was stored in the air for a specified period time of $t$, and then used the ratio of It/I0 to evaluate the resistance of the chip to air oxidation. Here, three different chips were tested: the first chip was a $\mathrm{Cu}$ chip obtained with a $\mathrm{Cu}$ deposition time of $3 \mathrm{~h}$, being referred to as $\mathrm{Cu}(3 \mathrm{~h})$ chip, the surface of which had a contact angle of $131.7^{\circ}$; the second was a Cu chip obtained with a $\mathrm{Cu}$ deposition time of $6 \mathrm{~h}$, being referred to as $\mathrm{Cu}(6 \mathrm{~h})$ chip, the surface of which had a contact angle of $144.0^{\circ}$; the third was a Cu-Ag chip that was obtained by depositing $\mathrm{Ag}$ for $1 \mathrm{~min}$ on the $\mathrm{Cu}(6 \mathrm{~h})$ chip, and it showed a contact angle of $141.0^{\circ}$. As shown in Figure 5, on the $\mathrm{Cu}(3 \mathrm{~h}) \mathrm{chip}$, the deposited $\mathrm{Cu}$ particles on the fabric were less densely packed and less hydrophobic, and the air oxidation during the storage of the chip was serious, which led to a fast decrease of the It/I0 ratio, only $6 \%$ of the response ability was kept after storing 60 days. In contrast, due to the much improved deposition of $\mathrm{Cu}$, the decrease of the $\mathrm{I}_{\mathrm{t}} / \mathrm{I}_{0}$ ratio on the $\mathrm{Cu}(6 \mathrm{~h})$ chip became considerably slower. For the $\mathrm{Cu}-\mathrm{Ag}$ SERS chip, its SERS performance maintained about $80 \%$ after storing in air for 60 days. It indicated that the $\mathrm{Cu}-\mathrm{Ag}$ chip with good hydrophobicity exhibited high oxidation resistance.

We also evaluated the stability of the SERS substrate by using an ethanol solution of $\mathrm{H}_{2} \mathrm{O}_{2}(0.01 \mathrm{M})$ to accelerate the oxidation of the substrate as shown in Figure 6a (curve 1). With the increase of oxidation time, the SERS signal intensity (in term of the $\mathrm{I}_{t} / \mathrm{I}_{0}$ ratio) of the as-prepared SERS chip (i.e., the oxidized chip) was rapidly decreased. When the oxidation time was $30 \mathrm{~min}$, the relative intensity of CV was decreased to $4 \%$ of the original one. It was very interesting that the great loss of the oxidized chip in the SERS signaling could be substantially recovered by an after-treatment through vacuum drying as shown in Figure 6a (curve 2). For example, the vacuum drying treatment could recover the relative SERS intensity of the chip being oxidized for $30 \mathrm{~min}$ from $4 \%$ to about $79 \%$. 


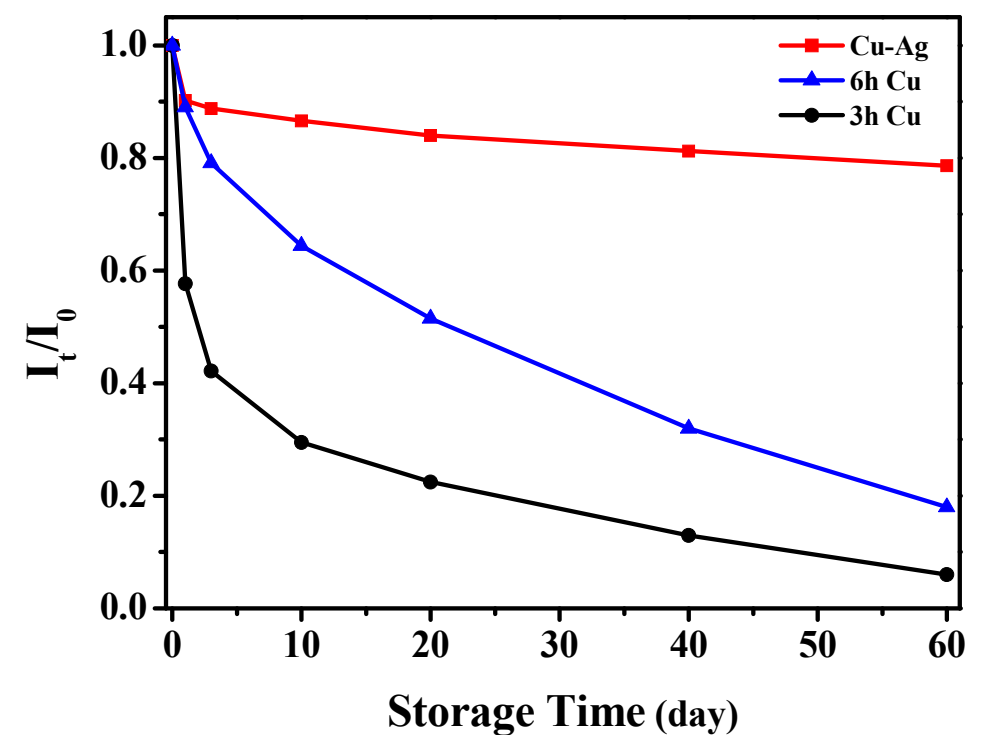

Figure 5. Endurances of SERS performances of various SERS chips to the air oxidation during storage: $\mathrm{Cu}(3 \mathrm{~h})$ chip, $\mathrm{Cu}(6 \mathrm{~h})$ chip and $\mathrm{Cu}-\mathrm{Ag}$ chip.
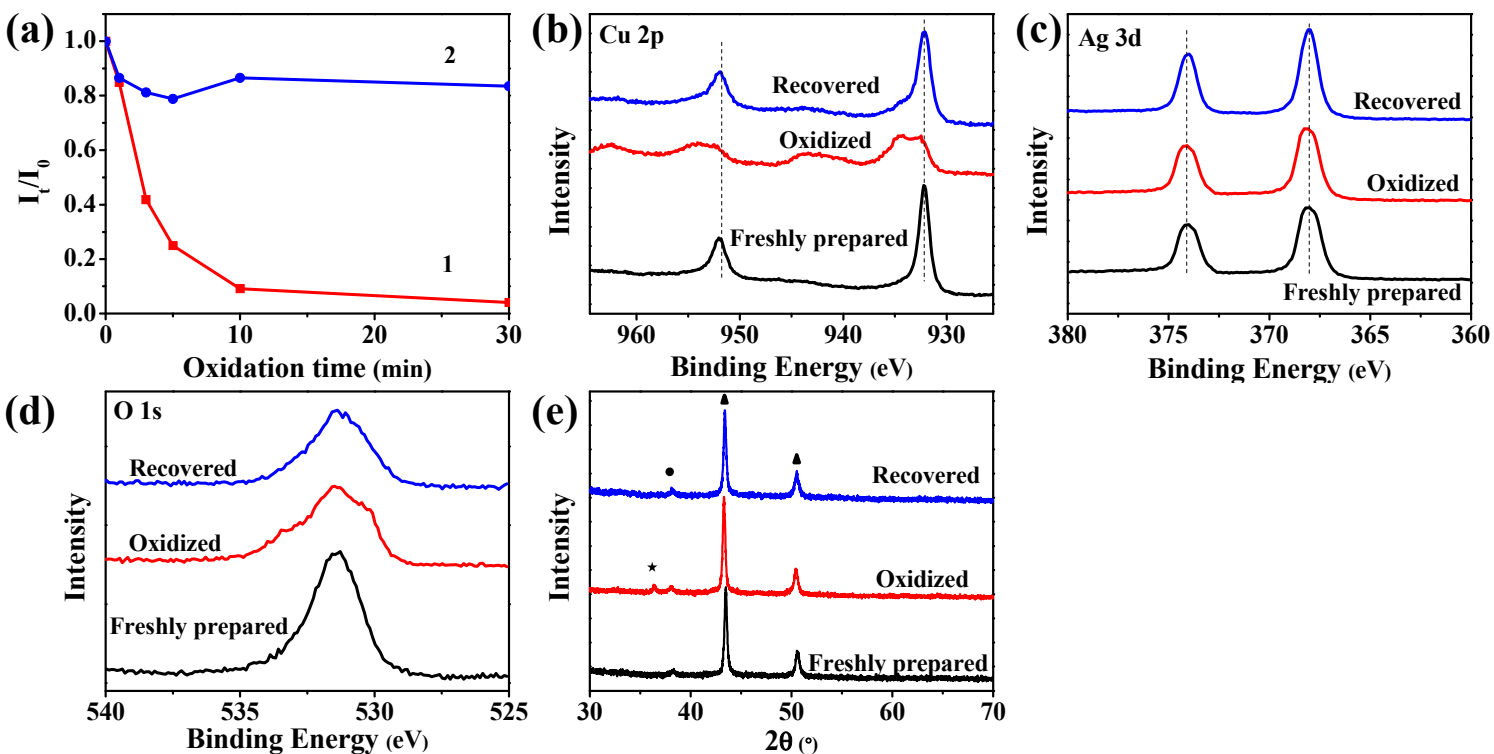

Figure 6. Recovering of the oxidized Cu-Ag SERS chip. (a) Dependence of the relative SERS intensity $\left(\mathrm{I}_{t} / \mathrm{I}_{0}\right)$ of the Cu-Ag chip on oxidation time (curve 1) and the recovered value after a vacuum drying treatment of the oxidized chip (curve 2). (b-d) XPS spectra of the freshly prepared, oxidized and recovered Cu-Ag chips: (b) Cu 2p, (c) Ag 3d, and (d) O 1s envelops. (e) XRD patterns of the freshly prepared, oxidized and recovered $\mathrm{Cu}-\mathrm{Ag}$ chips.

To understand what happened during the oxidation and the recovering treatment, we characterized the freshly prepared, oxidized and recovered $\mathrm{Cu}-\mathrm{Ag}$ chips by using XPS and XRD (Figure $6 b-e)$. As with that being discussed for Figure $2 b$, in the Cu 2p XPS spectrum of the freshly prepared $\mathrm{Cu}-\mathrm{Ag}$ chip there were two characteristic peaks of metallic copper at $952 \mathrm{eV}\left(\mathrm{Cu} 2 \mathrm{p}_{1 / 2}\right)$ and $932 \mathrm{eV}\left(\mathrm{Cu} 2 \mathrm{p}_{3 / 2}\right)$, both of which being attributed to metallic $\mathrm{Cu}$. However, in the spectrum of the oxidized chip (Figure 6b), the two peaks at $952 \mathrm{eV}$ and $932 \mathrm{eV}$ broadened towards the high binding energy region, indicating part of he copper converted to $\mathrm{Cu}(\mathrm{II})$, and two satellite peaks of $\mathrm{Cu}$ (II) appeared at $943 \mathrm{eV}$ and $963 \mathrm{eV}$. These suggested that the oxidation induced the generation of $\mathrm{Cu}(\mathrm{II})$ as the oxidation product. The recovering treatment made the spectrum of the oxidized chip almost the same as that 
of the freshly prepared $\mathrm{Cu}-\mathrm{Ag}$ chip. This meant that the recovering treatment by vacuum drying eliminated the oxidation product $\mathrm{Cu}$ (II) species.

Similarly, as discussed for the XPS Ag 3d spectrum of the fresh Cu-Ag chip in Figure 2c, the two peaks at $374 \mathrm{eV}\left(\mathrm{Ag} 3 \mathrm{~d}_{3 / 2}\right)$ and $368 \mathrm{eV}\left(\mathrm{Ag} \mathrm{3d_{5/2 }}\right)$ were attributed to the deposited metallic silver. The oxidation of the chip did not induce observable changes in the Ag $3 \mathrm{~d}$ XPS spectrum, and the recovering treatment yielded yet no observable changes in the Ag 3d XPS spectrum (Figure 6c). These hinted that neither the oxidation-induced loss of the chip in the SERS sensing nor its recovering was directly related to the deposited Ag particles.

As shown in Figure 6d, in the XPS O 1s spectrum of the fresh Cu-Ag chip, a peak was observed at $532 \mathrm{eV}$, which was attributed to organic C-O bonding of fabric. After the chip was oxidized for $30 \mathrm{~min}$, this peak became much broader, and its decovolution indicated that the oxygen was attached on the metal of $\mathrm{Cu}-\mathrm{Ag}$ chip after oxidization, among these peaks, those at $534 \mathrm{eV}$ and $530 \mathrm{eV}$ were assigned to the adsorbed oxygen and metal oxides, respectively [36,37]. After the recovering treatment, both the peaks at $534 \mathrm{eV}$ and $530 \mathrm{eV}$ were much depressed in the intensity. This suggested that the oxygen attached on metal was partly removed.

The XRD patterns of the freshly prepared $\mathrm{Cu}-\mathrm{Ag}$ chip are displayed in Figure 2a and were discussed before. After the oxidation, the oxidized $\mathrm{Cu}-\mathrm{Ag}$ chip exhibited a new peak from cupric oxide as shown in Figure 6e. The new peak at $36.4^{\circ}$ was assigned to the diffraction peak of $\left(\begin{array}{lll}1 & 1 & 1\end{array}\right)$ for the $\mathrm{Cu}_{2+1} \mathrm{O}$ (JCPDS 05-0667). $\mathrm{Cu}_{2+1} \mathrm{O}$ was $\mathrm{Cu}_{2} \mathrm{O}$ with metal excess defects, indicating that the $\mathrm{O}$ atom of it was easy to lose and lead to the oxygen vacancy $[38,39]$. A substantial part of the oxygen could be removed by the vacuum drying treatment. As confirmed by the XRD analysis, the diffraction peak of $\mathrm{Cu}_{2+1} \mathrm{O}$ for the oxidized chip was disappeared in the XRD patterns of the recovered $\mathrm{Cu}-\mathrm{Ag}$ chip. These results showed that the $\mathrm{O}$ atom of surface with low binding energy could be removed by vacuum drying, which substantially recovered the SERS performance of the oxidized $\mathrm{Cu}-\mathrm{Ag}$ SERS chip.

\subsection{Quantitative SERS Detection of Other Organic Compounds with the Cu-Ag Chip}

As discussed in Section 3.3 "SERS performances of the Cu-Ag chip", a SERS method was developed by using the $\mathrm{Cu}-\mathrm{Ag}$ chip for the detection of $\mathrm{CV}$, which gave a linear correspondence between the SERS intensity and the logarithm of $\mathrm{CV}$ concentration in the range of $10^{-9}-10^{-6} \mathrm{M}$, with a LOD as low as $10^{-11} \mathrm{M}$ (Figure $4 \mathrm{~b}, \mathrm{c}$ ). Here, we used this chip to detect more organic compounds to demonstrate its generality as a good SERS sensor.

As shown in Figure 7a, the SERS spectra of nine organic compounds with relatively strong Raman activity were acquired at $1 \mathrm{ppm}$. It was found that five of them could be detected on the $\mathrm{Cu}-\mathrm{Ag}$ chip, including sibutramine hydrochloride (SH), paraquat (PQ), rhodamine $b(\mathrm{RhB})$, crystal violet (CV) and methylene blue (MB), which were classified as Group 1. In contrast, the other four (cysteine (Cys), saccharin sodium (SS), melamine (MEL) and 4-mercaptobenzoic acid (4-MBA)), being classified as Group 2, could not be detected on this chip. This difference indicated that the $\mathrm{Cu}-\mathrm{Ag}$ chip had selective chemical enhancement for different targets due to $\mathrm{CM}$. The $\mathrm{CM}$ of Raman scattering was ascribed to the chemical interaction between metal-molecule, whereby the charge transfer (CT) in the metal-molecule system was supposed to alter the electron density distribution of molecules, resulting in greater polarizability and thus enhanced Raman scattering. The energy levels of HOMO/LUMO of the above targets were calculated by Gaussian method, and it was found that the minimum energy barrier for the charge transfer between metal and molecules in Group 1 (Figure $7 \mathrm{~b}$ ) were in the range of $0.54-1.31 \mathrm{eV}$, being considerably smaller than those of the molecules in Group 2 in the range of 2.03-4.66 eV (Figure 7c). Therefore, a charge transfer is easily induced by irradiating $785 \mathrm{~nm}$ laser, leading to the photo-induced charge transfer (PICT). The charge transfer between the metal-molecule pair may occur in the direction of metal-to-molecule or molecule-to-metal, which depends on the Fermi level of metal and the HOMO/LUMO levels of the molecule (Figure 7d) [37-39]. 
In the $\mathrm{Cu}-\mathrm{Ag}$ chip, the work function of $\mathrm{Cu}(4.65 \mathrm{eV})$ is higher than that of $\mathrm{Ag}(4.3 \mathrm{eV})$, and the electrons will transfer from $\mathrm{Ag}$ to $\mathrm{Cu}$ until the energy thermodynamic equilibrium level. Moreover, the Fermi level of $\mathrm{Ag}$ will be descended, and that of $\mathrm{Cu}$ will be raised up to attain the equilibrium level of $-4.475 \mathrm{eV}$. To achieve PICT by the laser of $785 \mathrm{~nm}(\Delta \mathrm{E}=1.58 \mathrm{eV})$, the target molecules should meet the requirement: HOMO level in the range of $-4.475 \mathrm{eV}$ to $-6.055 \mathrm{eV}$, or LUMO level in the range of $-2.895 \mathrm{eV}$ to $-4.475 \mathrm{eV}$. The molecules in Group 2 could not meet the above requirement, and hence there were no characteristic peaks in their SERS spectra obtained on the $\mathrm{Cu}-\mathrm{Ag}$ chip even at a concentration of $100 \mathrm{ppm}$, while the molecules in Group 1 meet the requirement and could all be detected at $1 \mathrm{ppm}$. Moreover, the stronger charge transfer will be achieved as the energy level is closer to Fermi level of $\mathrm{Cu}-\mathrm{Ag}$ chip. Due to the similar EM of substrate for adsorbed targets, the larger EF typically was achieved when the energy level of molecule was closer Fermi level. For example, the EF value of $\mathrm{SH}, \mathrm{MB}, \mathrm{CV}$ and $\mathrm{RhB}$ was $3.7 \times 10^{7}, 2.9 \times 10^{7}, 7.6 \times 10^{6}$ and $1.2 \times 10^{6}$ generally following an decreasing order in their minimum $|\Delta \mathrm{E}|$ between the $\mathrm{HOMO} / \mathrm{LUMO}$ of the molecules and Fermi of metal $(0.54 \mathrm{eV}, 0.87 \mathrm{eV}, 1.10 \mathrm{eV}$ and $1.31 \mathrm{eV})$. This clearly explained why the $\mathrm{Cu}-\mathrm{Ag}$ chip had a selectively to the detection of different target molecules.
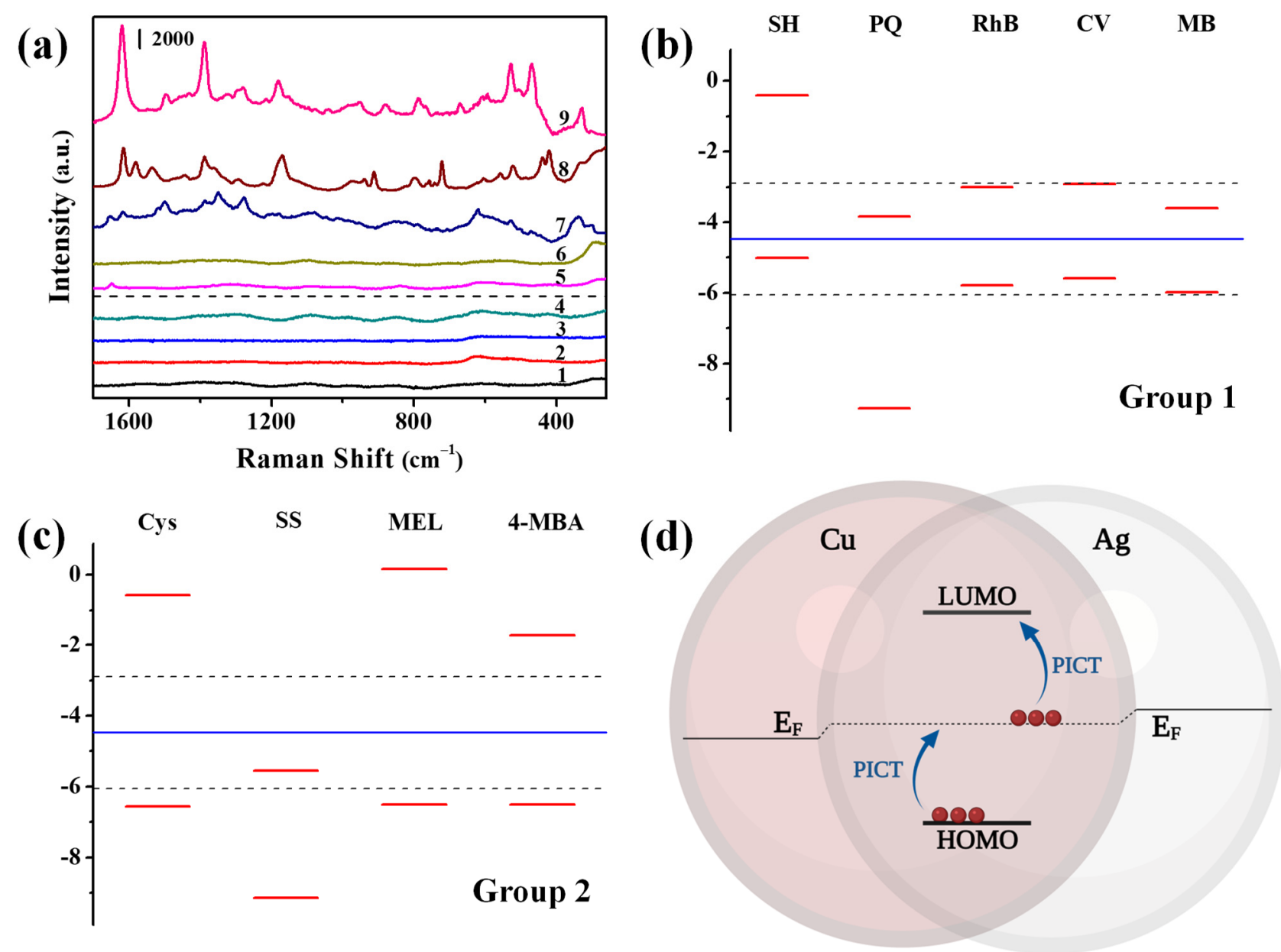

Figure 7. (a) SERE spectra of (1) Cys, (2) SS, (3) MEL, (4) 4-MBA, (5) SH, (6) PQ, (7) RhB (8) CV and (9) MB at 1 ppm on the $\mathrm{Cu}-\mathrm{Ag}$ SERS chip. The energy level diagram of the molecules in (b) Group 1 and (c) Group 2. (d) The electron transition model between $\mathrm{Cu}-\mathrm{Ag}$ chip and target molecules.

In comparison with $\mathrm{CV}$, the SERS activity of $\mathrm{SH}$ and $\mathrm{PQ}$ were much weaker, and hence we checked their quantitative detection to further evidence the merits of the $\mathrm{Cu}-\mathrm{Ag}$ chip (Figure 8). As their concentration was increased, their characteristic peaks became stronger. 
By using the strongest peak of each of the tested compounds, the SERS intensity was plotted against the logarithm of its concentration. It was found that the SERS intensity was well linearly correlated with the concentration in log scale for each compound. The linear range and LOD values were evaluated to be $10^{-8}-10^{-5} \mathrm{M}$ and $10^{-9} \mathrm{M}$ for $\mathrm{PQ}, 10^{-6}-10^{-3} \mathrm{M}$ and $10^{-7} \mathrm{M}$ for $\mathrm{SH}$, respectively. The wide linear ranges and low LOD values for all the tested targets indicated that the use of the $\mathrm{Cu}$-Ag SERS chip provided a good quantitative detection method for SERS analysis.

(a)

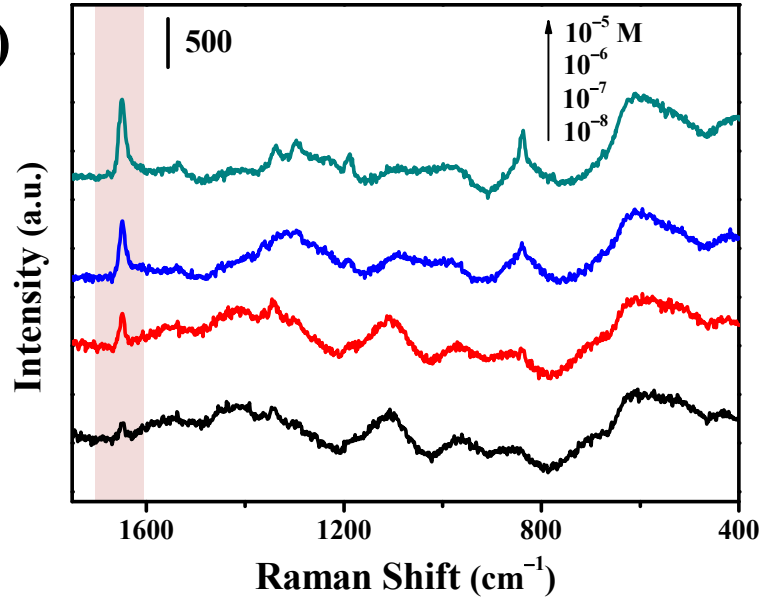

(c)

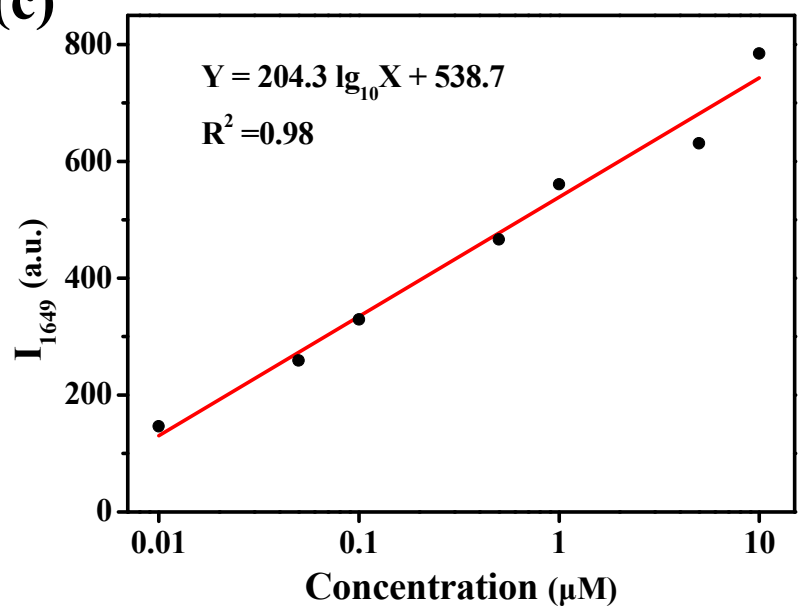

(b)

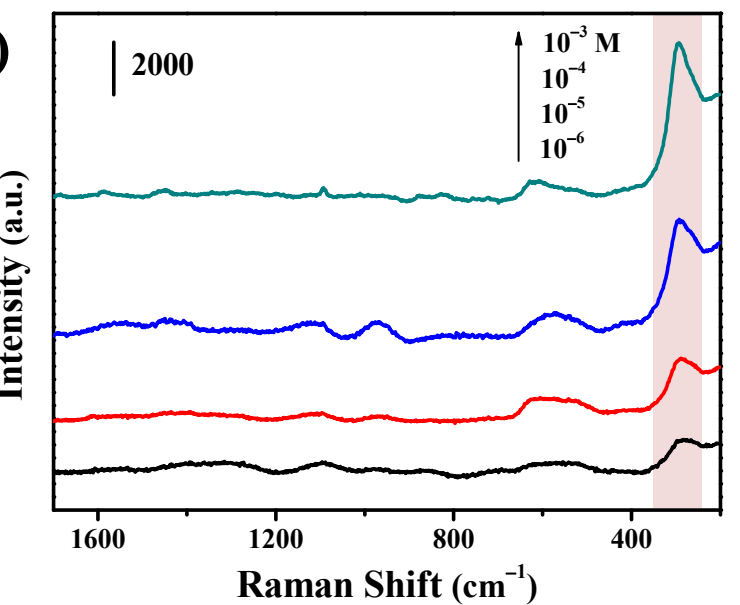

(d)

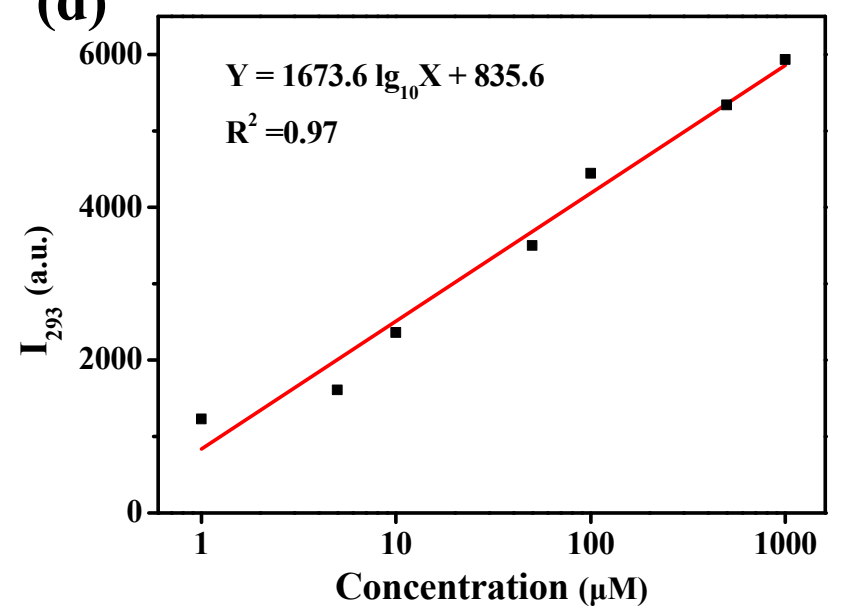

Figure 8. SERS spectra of (a) PQ and (b) SH at various concentrations on the Cu-Ag SERS chip. Linearity between the SERS intensity and $\log _{10}$ (concentration) of (c) PQ and (d) SH by using their strongest peaks.

\section{Conclusions}

In the present work, we have developed a sensitive and stable copper-based SERS chip by a chemical reduction method. The chemical deposition of $\mathrm{Cu}$ NPs on the fabric support ensured the $\mathrm{Cu}$ chip had no background interference of stabilizers because no stabilizers were used in the preparation. This permitted the quantitative detection of $\mathrm{CV}$ in a range from $10^{-8} \mathrm{M}$ to $10^{-5} \mathrm{M}$ with an LOD as low as $10^{-8} \mathrm{M}$. By considering the further improvement of the SERS enhancing effect and the air oxidation resistance of the $\mathrm{Cu}$ chip, a very thin layer of Ag NPs was deposited on the Cu chip by a replacement reaction. The introduction of $\mathrm{Ag}$ further enhanced the SERS performance of $\mathrm{Cu}$ chip, and the EF was increased from $2.0 \times 10^{6}$ to $7.6 \times 10^{6}$ after modification with Ag. Both the hydrophobicity and Ag shell improved the oxidation resistance of the $\mathrm{Cu}-\mathrm{Ag}$ SERS chip, the SERS intensity kept $80 \%$ of the original signal after storing in the air for 60 days. The $\mathrm{O}$ atoms on the oxidized substrate could even be removed by vacuum drying to restore its SERS performance. The as-prepared $\mathrm{Cu}$-Ag chip was used for detection of various targets, 
and results indicated that the molecules with required energy levels could be selectively detected at $1 \mathrm{ppm}$ due to the $\mathrm{CM}$ caused by photo-induced charge transfer. The SERS method on this $\mathrm{Cu}-\mathrm{Ag}$ chip also showed a wide linearity range and low LOD values for the quantitative detection of these organic compounds.

Author Contributions: Methodology and writing—original draft preparation, P.D.; investigation, H.L.; validation, X.H.; software, N.W.; project administration, L.Z. All authors have read and agreed to the published version of the manuscript.

Funding: This research was funded by the National Natural Science Foundation of China grant number 22076052, 21976063. And The APC was funded by the National Natural Science Foundation of China grant number 22076052.

Acknowledgments: The authors acknowledge the financial support from the National Natural Science Foundation of China (Grant No. 22076052, 21976063). The electron transition model diagram was created with BioRender.com.

Conflicts of Interest: The authors declare no conflict of interest.

\section{References}

1. Haynes, C.L.; McFarland, A.D.; Duyne, R.P.V. Surface-enhanced Raman spectroscopy. Anal. Chem. 2005, 77, 338 A-346 A. [CrossRef]

2. Jiang, Y.; Sun, D.; Pu, H.; Wei, Q. Surface-enhanced Raman Spectroscopy (SERS): A novel reliable technique for rapid detection of common harmful chemical residues. Trends Food Sci. Tech. 2018, 75, 10-22. [CrossRef]

3. Wei, H.; Xu, H. Hot spots in different metal nanostructures for plasmon-enhanced Raman spectroscopy. Nanoscale 2013, 5, 10794-10805. [CrossRef] [PubMed]

4. Tan, T.; Tian, C.; Ren, Z.; Yang, J.; Chen, Y.; Sun, L.; Li, Z.; Wu, A.; Yin, J.; Fu, H. LSPR-dependent SERS performance of silver nanoplates with highly stable and broad tunable LSPRs prepared through an improved seed-mediated strategy. Phys. Chem. Chem. Phys. 2013, 15, 21034-21042. [CrossRef] [PubMed]

5. Athira, K.; Ranjana, M.; Bharathi, M.S.S.; Reddy, B.N.; Babu, T.G.S.; Rao, S.V.; Kumar, D.V.R. Aggregation induced, formaldehyde tailored nanowire like networks of $\mathrm{Cu}$ and their SERS activity. Chem. Phys. Lett. 2020, 748, 137390. [CrossRef]

6. Qiu, H.; Xu, S.; Chen, P.; Gao, S.; Li, Z.; Zhang, C.; Jiang, S.; Liu, M.; Li, H.; Feng, D. A novel surface-enhanced Raman spectroscopy substrate based on hybrid structure of monolayer graphene and $\mathrm{Cu}$ nanoparticles for adenosine detection. Appl. Surf. Sci. 2015, 332, 614-619. [CrossRef]

7. Chen, H.; Lin, M.; Wang, C.; Chang, Y.; Gwo, S. Large-scale hot spot engineering for quantitative SERS at the single-molecule scale. J. Am. Chem. Soc. 2015, 137, 13698-13705. [CrossRef]

8. Kleinman, S.L.; Sharma, B.; Blaber, M.G.; Henry, A.; Valley, N.; Freeman, R.G.; Natan, M.J.; Schatz, G.C.; Duyne, R.P.V. Structure enhancement factor relationships in single gold nanoantennas by surface-enhanced Raman excitation spectroscopy. J. Am. Chem. Soc. 2013, 135, 301-308. [CrossRef] [PubMed]

9. Kowalska, A.A.; Kaminska, A.; Adamkiewicz, W.; Witkowska, E.; Tkacz, M. Novel highly sensitive Cu-based SERS platforms for biosensing applications. J. Raman Spectrosc. 2015, 46, 428-433. [CrossRef]

10. Rao, G.; Jian, X.; Lv, W.; Zhu, G.; Xiong, J.; He, W. A highly-efficient route to three-dimensional nanoporous copper leaves with high surface enhanced Raman scattering properties. Chem. Eng. J. 2017, 321, 394-400. [CrossRef]

11. Li, Z.; Jiang, S.; Xu, S.; Zhang, C.; Qiu, H.; Li, C.; Sheng, Y.; Huo, Y.; Yang, C.; Man, B. Few-layer MoS2-encapsulated Cu nanoparticle hybrids fabricated by two-step annealing process for surface enhanced Raman scattering. Sens. Actuators B-Chem. 2016, 230, 645-652. [CrossRef]

12. Dizajghorbani-Aghdam, H.; Miller, T.S.; Malekfar, R.; McMillan, P.F. SERS-active Cu nanoparticles on carbon nitride support fabricated using pulsed laser ablation. Nanomaterials 2019, 9, 1223. [CrossRef] [PubMed]

13. Jiang, W.; Shan, W.; Ling, H.; Wang, Y.; Cao, Y.; Li, X. Surface-enhanced Raman scattering of patterned copper nanostructure electrolessly plated on arrayed nanoporous silicon pillars. J. Phys. Condens. Matter 2010, 22, 415105. [CrossRef] [PubMed]

14. Shao, Q.; Que, R.; Shao, M.; Cheng, L.; Lee, S. Copper Nanoparticles Grafted on a Silicon Wafer and Their Excellent SurfaceEnhanced Raman Scattering. Adv. Funct. Mater. 2012, 22, 2067-2070. [CrossRef]

15. Pereira, A.J.; Gomes, J.P.; Lenz, G.F.; Schneider, R.; Chaker, J.A.; de Souza, P.E.N.; Felix, J.F. Facile shape-controlled fabrication of copper nanostructures on borophosphate glasses: Synthesis, characterization, and their highly sensitive Surface-Enhanced Raman Scattering (SERS) properties. J. Phys. Chem. C 2016, 120, 12265-12272. [CrossRef]

16. Ding, Q.; Hang, L.; Ma, L. Controlled synthesis of $\mathrm{Cu}$ nanoparticle arrays with surface enhanced Raman scattering effect performance. RSC Adv. 2018, 8, 1753-1757. [CrossRef]

17. Gill, A.A.S.; Singh, S.; Nate, Z.; Chauhan, R.; Thapliyal, N.B.; Karpoormath, R.; Maru, S.M.; Reddy, T.M. A novel copper-based 3D porous nanocomposite for electrochemical detection and inactivation of pathogenic bacteria. Sens. Actuators B-Chem. 2020, 321, 128449. [CrossRef] 
18. Ouyang, L.; Wang, Y.; Zhu, L.; Irudayaraj, J.; Tang, H. Filtration-assisted fabrication of large-area uniform and long-term stable graphene isolated nano-ag array membrane as surface enhanced Raman scattering substrate. Adv. Mater. Interfaces 2018, 5, 1701221. [CrossRef]

19. Ban, R.; Yu, Y.; Zhang, M.; Yin, J.; Xu, B.; Wu, D.; Wu, M.; Zhang, Z.; Tai, H.; Li, J.; et al. Synergetic SERS enhancement in a metal-like/metal double-shell structure for sensitive and stable application. ACS Appl. Mater. Interfaces 2017, 9, 13564-13570. [CrossRef]

20. Zhang, X.; Shi, C.; Liu, E.; Li, J.; Zhao, N.; He, C. Nitrogen-doped graphene network supported copper nanoparticles encapsulated with grapheme shells for surface-enhanced Raman scattering. Nanoscale 2015, 7, 17079-17087. [CrossRef]

21. Li, J.; Huang, Y.; Ding, Y.; Yang, Z.; Li, S.; Zhou, X.; Fan, F.; Zhang, W.; Zhou, Z.; Wu, D.; et al. Shell-isolated nanoparticle-enhanced Raman spectroscopy. Nature 2010, 464, 392-395. [CrossRef] [PubMed]

22. Yang, M.; Chen, T.; Lau, W.; Wang, Y.; Tang, Q.; Yang, Y.; Chen, H. Development of polymer-encapsulated metal nanoparticles as surface-enhanced Raman scattering probes. Small 2009, 5, 198-202. [CrossRef]

23. Shen, A.; Chen, L.; Xie, W.; Hu, J.; Zeng, A.; Richards, R.; Hu, J. Triplex Au-Ag-C core-shell nanoparticles as a novel Raman label. Adv. Funct. Mater. 2010, 20, 969-975. [CrossRef]

24. Xu, S.; Man, B.; Jiang, S.; Wang, J.; Wei, J.; Xu, S.; Liu, H.; Gao, S.; Liu, H.; Li, Z.; et al. Graphene/Cu nanoparticle hybrids fabricated by chemical vapor deposition as surface-enhanced Raman scattering substrate for label-free detection of adenosine. ACS Appl. Mater. Interfaces 2015, 7, 10977-10987. [CrossRef]

25. Huang, L.; Zhang, L.; Song, J.; Wang, X.; Liu, H. Superhydrophobic nickel-electroplated carbon fibers for versatile oil/water separation with excellent reusability and high environmental stability. ACS Appl. Mater. Interfaces 2020, 12, 24390-24402. [CrossRef]

26. Yang, W.; Li, J.; Zhou, P.; Zhu, L.; Tang, H. Superhydrophobic copper coating: Switchable wettability, on-demand oil-water separation, and antifouling. Chem. Eng. J. 2017, 327, 849-854. [CrossRef]

27. Aghajani, S.; Accardo, A.; Tichem, M. Aerosol direct writing and thermal tuning of copper nanoparticle patterns as surfaceenhanced Raman scattering sensors. ACS Appl. Nano Mater. 2020, 3, 5665-5675. [CrossRef]

28. Diao, F.; Xiao, X.; Luo, B.; Sun, H.; Ding, F.; Ci, L.; Si, P. Two-step fabrication of nanoporous copper films with tunable morphology for SERS application. Appl. Surf. Sci. 2018, 427, 1271-1279. [CrossRef]

29. Yan, X.; Wang, Y.; Shi, G.; Wang, M.; Zhang, J.; Sun, X.; Xu, H. Flower-like Cu nanoislands decorated onto the cicada wing as SERS substrates for the rapid detection of crystal violet. Optik 2018, 172, 812-821. [CrossRef]

30. Lim, H.; Kim, D.; Kim, Y.; Nagaura, T.; You, J.; Kim, J.; Kim, H.; Na, J.; Henzie, J.; Yamauchi, Y. A mesopore-stimulated electromagnetic near-field: Electrochemical synthesis of mesoporous copper films by micelle self-assembly. J. Mater. Chem. A 2020, 8, 21016-21025. [CrossRef]

31. Mao, A.; Ding, M.; Jin, X.; Gu, X.; Cai, C.; Xin, C.; Zhang, T. Direct, rapid synthesis of water-dispersed copper nanoparticles and their surface-enhanced Raman scattering properties. J. Mol. Struct. 2015, 1079, 396-401. [CrossRef]

32. Ramani, T.; Prasanth, K.L.; Sreedhar, B. Air stable colloidal copper nanoparticles: Synthesis, characterization and their surfaceenhanced Raman scattering properties. Physica E 2016, 77, 65-71. [CrossRef]

33. Balčytis, A.; Ryu, M.; Seniutinas, G.; Juodkazyte, J.; Cowie, B.C.C.; Stoddart, P.R.; Zamengo, M.; Morikawa, J.; Juodkazis, S. Black-CuO: Surface-enhanced Raman scattering and infrared properties. Nanoscale 2015, 7, 18299-18304. [CrossRef]

34. Proniewicz, E.; Vantasin, S.; Olszewski, T.K.; Boduszek, B.; Ozaki, Y. Biological application of water-based electrochemically synthesized $\mathrm{CuO}$ leaf-like arrays: SERS response modulated by the positional isomerism and interface type. Phys. Chem. Chem. Phys. 2017, 19, 31842-31855. [CrossRef]

35. Yang, L.; Liu, D.; Cui, G.; Xie, Y. $\mathrm{Cu}_{2}+1 \mathrm{O} /$ graphene nanosheets supported on three dimensional copper foam for sensitive and efficient non-enzymatic detection of glucose. RSC Adv. 2017, 7, 19312-19317. [CrossRef]

36. Cao, X.; Cui, L.; Liu, B.; Liu, Y.; Jia, D.; Yang, W.; Razal, J.M.; Liu, J. Reverse synthesis of star anise-like cobalt doped Cu$\mathrm{MOF} / \mathrm{Cu}_{2}+1 \mathrm{O}$ hybrid materials based on a $\mathrm{Cu}(\mathrm{OH})_{2}$ precursor for high performance supercapacitors. J. Mater. Chem. A 2019, 7, 3815-3827. [CrossRef]

37. Wang, Y.; Liu, J.; Ozaki, Y.; Xu, Z.; Zhao, B. Effect of $\mathrm{TiO}_{2}$ on altering direction of interfacial charge transfer in a TiO2-Ag-MPY-FePc system by SERS. Angew. Chem. Int. Ed. 2019, 58, 8172-8176. [CrossRef] [PubMed]

38. Wang, X.; Guo, L. SERS activity of semiconductors: Crystalline and amorphous nanomaterials. Angew. Chem. Int. Ed. 2020, 59, 4231-4239. [CrossRef]

39. Jensen, L.; Aikens, C.M.; Schatz, G.C. Electronic structure methods for studying surface-enhanced Raman scattering. Chem. Soc. Rev. 2008, 37, 1061-1073. [CrossRef] 